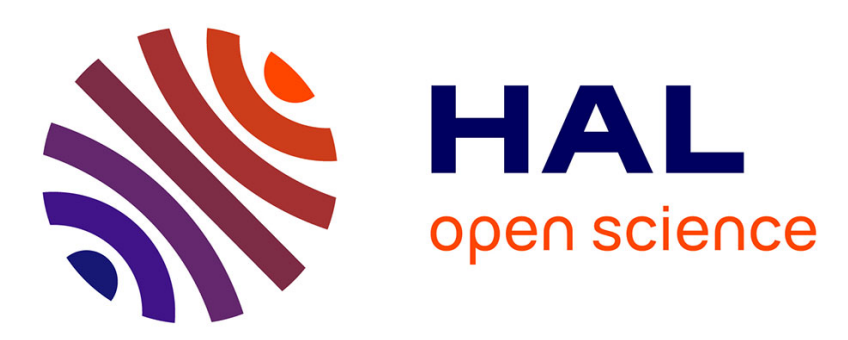

\title{
Effects of rubbers and thermoplastics as additives on cyanate polymerization
}

\author{
Zhiqiang Cao, Françoise Méchin, Jean-Pierre Pascault
}

\section{To cite this version:}

Zhiqiang Cao, Françoise Méchin, Jean-Pierre Pascault. Effects of rubbers and thermoplastics as additives on cyanate polymerization. Polymer international, 1994, 34 (1), pp.41-48. 10.1002/pi.1994.210340107 . hal-02046001

\section{HAL Id: hal-02046001 \\ https://hal.science/hal-02046001}

Submitted on 29 Jan 2020

HAL is a multi-disciplinary open access archive for the deposit and dissemination of scientific research documents, whether they are published or not. The documents may come from teaching and research institutions in France or abroad, or from public or private research centers.
L'archive ouverte pluridisciplinaire HAL, est destinée au dépôt et à la diffusion de documents scientifiques de niveau recherche, publiés ou non, émanant des établissements d'enseignement et de recherche français ou étrangers, des laboratoires publics ou privés. 


\title{
Effects of Rubbers and Thermoplastics as Additives on Cyanate Polymerization
}

\author{
ZhiQiang Cao, Françoise Méchin \& Jean-Pierre Pascault* \\ Laboratoire des Matériaux Macromoléculaires, URA CNRS 507, \\ Institut National des Sciences Appliquées de Lyon,
}

Bât. 403, 20, avenue Albert Einstein, 69621 Villeurbanne Cedex, France

\begin{abstract}
Several rubber (acrylonitrile-butadiene copolymer) or thermoplastic (polyethersulfone) additives bearing different chain ends were introduced into pure aromatic dicyanates. We studied the influence of these initially miscible modifiers on the polymerization kinetics, as a function of their chemical structure and concentration. It appears that apart from those bearing a labile hydrogen atom, the additives play almost no role on the polycyclotrimerization rate; neither does phase separation. However, the additives influence the structure of the final networks insofar as they partially dissolve in the matrix and thus modify both the final $T_{g}$ and the onset of vitrification, compared with the pure monomer. Finally, the amino- or phenolic additives can react with cyanate functions and produce adducts which are well-known catalysts for cyanate cyclotrimerization; in their presence, a marked enhancement of the polymerization rate can thus be observed, together with the thermal effects mentioned above.
\end{abstract}

Key words: modified cyanates, polymerization kinetics, phase separation.

Published in Polymer International, vol. 34, 41-48 (1994)

* To whom correspondence should be addressed. 


\section{INTRODUCTION}

Brittle thermosets are best toughened by the introduction of a rubbery or thermoplastic second phase. The main factors which determine toughening effects are the final polymer blend morphology and the adhesion between the two phases. For initially miscible reactive systems, the latter depends not only on the chemical and physical properties of both the additive and the monomer, but also strongly on the polymerization reaction. ${ }^{1,2}$ The phase separation and morphology formation are very intricate phenomena; their study remains limited up to now, and for thermosetting systems is mainly focused on rubber-toughened polyepoxy matrices. ${ }^{3,4}$

Chan et $a^{\beta}$ investigated the effect of cure conditions on the transitions and morphologies of two rubber-modified epoxy systems (based on bisphenol A diglycidyl ether, DGEBA, and trimethyleneglycol di-4-aminobenzoate). They found that the chemistry was essentially the same for the epoxyterminated butadiene-acrylonitrile random copolymer (ETBN)-modified system and for the neat system. On the other hand, the chemistry is different for amino-terminated butadiene-acrylonitrile random copolymer (ATBN)-modified systems, because ATBN and the residual piperazine in ATBN can not only react with epoxy prepolymer but can also promote epoxy homopolymerization.

The morphologies of rubber-modified systems were also dependent on the isothermal curing temperature. Volume fractions of dispersed phase for ATBN-modified systems were particularly sensitive to the cure conditions.

Verchère $e t a l^{5}$ indicated that the presence of ETBN in an epoxy-diamine reactive mixture (DGEBA and 4,4'-diamino-3,3'-dimethyldicyclohexylmethane)did not change the polymerization kinetics, even after phase separation. Yet the gel conversion $x_{\text {gel }}$, was a little higher with 15 wt\% ETBN than for the neat system. This change was attributed to an unbalanced stoichiometry between epoxy and amine functions, due to the phase separation.

On the other hand, a further study on the same system by Chen et $a l^{6}$ produced different conclusions. This work pointed out that the gel conversion and overall network build-up were not affected by the presence of rubber (ETBN, ATBN or carboxy-terminated rubber, CTBN), whereas the polymerization kinetics were disturbed. It was found that the dilution effect plays a minor role, but the catalytic effect of a rubber additive can play a significant role in the polymerization, depending on the additive end groups; but in all these rubber-modified epoxies, the phase separation has no direct influence on the polymerization rate and evolution of viscosity.

Rozenberg ${ }^{2}$ concluded that whatever the reasons for the change of thermodynamic parameters of the system, the realizable morphology was determined by the given kinetics of a process. He confirmed this conclusion by experiments in which the rate of the curing process was varied with the addition of small quantities of catalyst in a rubber-poxy system. In so doing, the thermodynamic characteristics of the process remained practically unchanged. The experiments showed that a variation of the polymerization rate could change the average size and size distribution of the dispersed phase particles.

Cyanate ester resins are the key monomers for a new type of high performance polymer. They have been developed by Hi-Tek Polymers (then Rhône-Poulenc and now Ciba-Geigy) during the 1980s. The polycyclotrimerization of cyanates can take place by simple heating, or can be catalysed by transition metal cations together with labile hydrogen compounds, e.g. phenols, alcohols or amines. ${ }^{7}$ 
<smiles>[R]Oc1nc(O[R])nc(O[R])n1</smiles>

However, the polycyanurate networks often display a somewhat poor toughness. ${ }^{7-11}$ Rubbers or thermoplastics have been used to improve their mechanical properties. The relation between these properties and morphology was studied, but no attempt was made to determine either the relation between the morphology and the phase separation mechanism, or the effect of the additive on the polymerization reaction.

In the present work, we describe the effects of different liquid butadiene-acrylonitrile rubbers and of polyethersulfones (PES) on the polycyclotrimerization of 1,1-bis(4-cyanatophenyl)ethane (L10) and 2,2-bis(4-cyanatophenyl)propane (B10). The polymerization kinetics, as well as the glass transition temperatures of the final materials, were investigated as a function of the amount of additives and of the nature of their chain ends.

\section{EXPERIMENTAL}

\section{Monomers}

The cyanate monomers (Arocy L10 and B10) were provided by Rhône-Poulenc Inc., Louisville, KY, USA, and were used as received. Liquid L10 contains 2-3\% impurities (trimer, monophenol-monocyanate and ortho-para substituted isomers). B10 is a high purity (>99.5\%) crystalline powder $\left(T_{f}=79^{\circ} \mathrm{C}\right)$. The chemical structures of these monomers are shown in Table 1.

\section{Additives}

Acrylonitrile-butadiene rubbers were provided by BF Goodrich, Brecksville, $\mathrm{OH}, \mathrm{USA}$. Their structures, together with that of the two PES (Victrex, ICI) used in this study, are given in Tables 2 and 3.

The rubbers have the same chain composition and molar mass but different end groups, and have been characterized in a previous work. ${ }^{6}$ The ATBN rubber was obtained by reacting CTBN with an excess of diamine, Unilink 4200 (from UOP, USA).

The two PES have different molar masses and different concentrations of phenolic end groups. By ' $\mathrm{H}$ NMR we have estimated that PES 4100P is a non-reactive oligomer, contrary to PES 5003P which has approximately one $\mathrm{OH}$ per molecule.

TABLE 1. Chemical structures and main characteristics of the dicyanate monomers

\begin{tabular}{|c|c|c|c|c|}
\hline $\begin{array}{c}\text { Commercial } \\
\text { name }\end{array}$ & Chemical structure & $\mathrm{M}(\mathrm{g} / \mathrm{mol})$ & $\rho\left(\mathrm{g} / \mathrm{cm}^{3}\right)$ & $\delta(\sqrt{\mathrm{MPa}}$ \\
\hline Arocy L10 & & 264 & 1.18 & 23.06 \\
Arocy B10 & & 278 & 1.26 & 24.24 \\
\hline
\end{tabular}


TABLE 2. Chemical structures and characteristics of the elastomer additives

\begin{tabular}{|c|c|c|c|c|}
\hline & NFBN & CTBN & ATBN & Unilink 4200 \\
\hline $\begin{array}{l}\text { Chemical } \\
\text { structure }^{a}\end{array}$ & $\begin{array}{cc}\mathrm{CH}_{3} & \mathrm{CH}_{3} \\
\mathrm{CH}_{3}-\underset{\mathrm{C}}{\mathrm{C}}-(\mathrm{R}) & -\mathrm{C}-\mathrm{CH}_{3} \\
\mathrm{CN} & \mathrm{CN}\end{array}$ & $\mathrm{HOOCCH}_{2} \mathrm{CH}_{2}-\underset{\mathrm{C}}{\mathrm{C}} \underset{\mathrm{C}}{\mathrm{C}}(\mathrm{R}) \stackrel{\mathrm{CN}}{-\mathrm{C}}-\mathrm{CH}_{2} \mathrm{CH}_{2} \mathrm{COOH}$ & 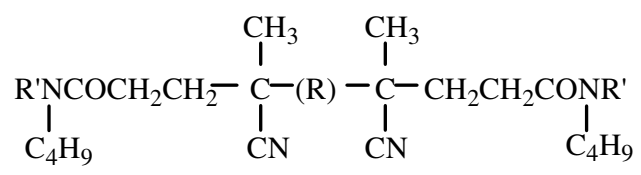 & 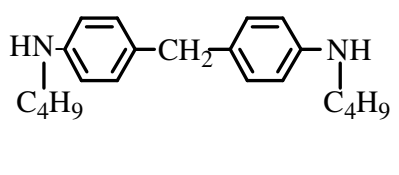 \\
\hline Functionality & 0 & $1.8(\mathrm{COOH})$ & $1.9\left(\mathrm{NHR}^{\prime}\right)$ & $2.0\left(\mathrm{NHC}_{4} \mathrm{H}_{9}\right)$ \\
\hline \% Acrylonitrile & 17.2 & 18.0 & 18.0 & 0 \\
\hline$\overline{M_{n}}(\mathrm{~g} / \mathrm{mol})$ & 3600 & 3600 & $3600+10 \%$ excess Unilink 4200 & 310 \\
\hline$\frac{\overline{M_{w}}}{\overline{M_{n}}}$ & $2.1^{b}$ & $1.9^{b}$ & 2.8 (polymer peak) $^{b}$ & 1.0 \\
\hline$\delta(\sqrt{\mathrm{MPa}})$ & 18.3 & 18.3 & 18.4 & - \\
\hline$T_{\mathrm{g}}\left({ }^{\circ} \mathrm{C}\right)$ & -67 & -60 & -47 & _ \\
\hline
\end{tabular}

${ }^{a} \mathrm{R}=-\left(\mathrm{CH}_{2}-\mathrm{CH}=\mathrm{CH}-\mathrm{CH}_{2}\right)_{\mathrm{a}} \underset{\mathrm{C}}{\left(\mathrm{CH}_{2}-\mathrm{CH}\right)_{\mathrm{b}}} \underset{\mathrm{CH}=\mathrm{CH}_{2} \quad\left(\mathrm{CH}_{2}-\mathrm{CH}\right)_{\mathrm{c}}}{\mathrm{CN}}$<smiles>[R]=CCCCNc1ccc(Cc2ccc(C)cc2)cc1</smiles>

${ }^{b}$ From size exclusion chromatography measurements (polystyrene standards). 
TABLE 3. Chemical structures and characteristics of the PES additives

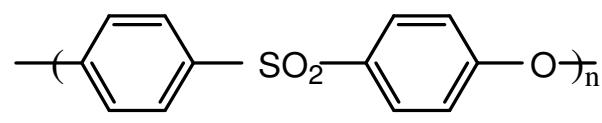

\begin{tabular}{|c|c|c|c|c|c|}
\hline Reference & $\overline{M_{n}^{a}}$ & $\overline{\overline{M_{w}}}$ & $T_{\mathrm{g}}\left({ }^{\circ} \mathrm{C}\right)^{\mathrm{b}}$ & $\delta(\sqrt{\mathrm{MPa}})$ & $\rho\left(\mathrm{g} / \mathrm{cm}^{3}\right)\left(25^{\circ} \mathrm{C}\right)$ \\
\hline PES 4100P & 15200 & 2.7 & 216 & 23.1 & 1.37 \\
PES 5003P & 21900 & 2.1 & 222 & 23.1 & $/$ \\
\hline
\end{tabular}

${ }^{a}$ From size exclusion chromatography measurements in dimethylformamide at $80^{\circ} \mathrm{C}$.

${ }^{b}$ From DSC measurements.

\section{Preparation of the blends}

The blends PES 4100P/L10 were prepared by adding L10 to a dichloromethane solution of PES 4100P, then vacuum drying at $\approx 60^{\circ} \mathrm{C}$.

The blends PES $5003 \mathrm{P} / \mathrm{L} 10$ were prepared by stirring at $\approx 90^{\circ} \mathrm{C}$ for about $1 \mathrm{~h}$ when $\Phi_{a}$ (weight fraction of the additive) $\leq 0.12$. When $\Phi_{a}>0.12$, a better mixing was achieved with the help of some dichloromethane; the blend was then dried at $60^{\circ} \mathrm{C}$ under vacuum.

The other blends, based on acrylonitrile-butadiene rubbers, were prepared by simple manual stirring for $10 \mathrm{~min}$ at room temperature.

\section{Polymerization reaction}

- The DSC pan, containing 10-15 mg of sample, was sealed under air. It was then placed in the oven at $180^{\circ} \mathrm{C}$ and reacted there.

- About $2 \mathrm{~g}$ of sample were placed in a test tube in order to measure the temperature at the cloud point $\left(T_{\mathrm{cp}}\right)$. The isothermal polymerization was then carried out in situ inside the light transmission device. ${ }^{12}$ Once the blend was cloudy, the test tube was taken out and chilled in ice, so that the time and conversion at the cloud point, $t_{\mathrm{cp}}$ and $x_{\mathrm{cp}}$, could be obtained.

\section{DSC measurements}

A Mettler TA3000 microcalorimeter was used for measuring the $T_{\mathrm{g}}$ values and residual heats of reaction $\Delta H$ of different samples, by scanning from -100 to $360^{\circ} \mathrm{C}$ (heating rate: $10 \mathrm{~K} / \mathrm{min}$ ). The initial cyanate group conversion, $x$, was calculated by assuming that $100 \%-O C N$ groups were reacted when scanning:

$$
x=\frac{\Delta H_{0}-0.97 \Delta H}{\Delta H_{0}}
$$

where $\Delta H_{0}$ is the measured heat of reaction for the initial monomer; the factor 0.97 comes from the fact that our batch of L10 has already a conversion $x=0-03$. For B10 studies, as the monomer is pure, the factor is unity. 


\section{Gelation measurement}

The gel time, $t_{\mathrm{gel}}$, of rubber/cyanate blends was determined as the time at which insolubles appear in THF. That of PES/cyanate was determined by dynamic mechanical analysis (RDA-700).

\section{RESULTS AND DISCUSSION}

\section{Polymerization reaction}

First, the reactive systems were studied at different isothermal curing temperatures, $T_{\mathrm{i}}=180^{\circ} \mathrm{C}$ for systems based on $\mathrm{L} 10$, and $T_{\mathrm{i}}=200^{\circ} \mathrm{C}$ for those based on B10 (less reactive).

The increase in cyanate conversion $x$ during the isothermal cures of neat L10 or B10 was monitored as a function of time by DSC; the results are shown in Figs 1 and 2. The $x=f(t)$ curves display a marked Sshape, revealing an autocatalytic character for the reaction involved. Gupta, ${ }^{13}$ as well as Simon \& Gillham for a different monomer, ${ }^{14}$ found similar results, and the latter proposed the following equation:

$$
\frac{d x}{d t}=k_{1}(1-x)^{2}+k_{2} x(1-x)^{2}
$$

to account for the observed $x=\mathrm{f}(t)$ curve. In this equation, $k_{1}$ and $k_{2}$ are the rate constants for the second-order and second-order autocatalysed reaction, respectively.

In our laboratory, ${ }^{15}$ this equation was successfully applied to the isothermal polycyclotrimerization of B10 under air, whereas it was not the case for L10. ${ }^{16}$ This was attributed to the greater amount of impurities in L10: in addition to trimer, it contains monophenol-monocyanate, and catalytic residues from its synthesis (triethylamine and diethylcyanamide).

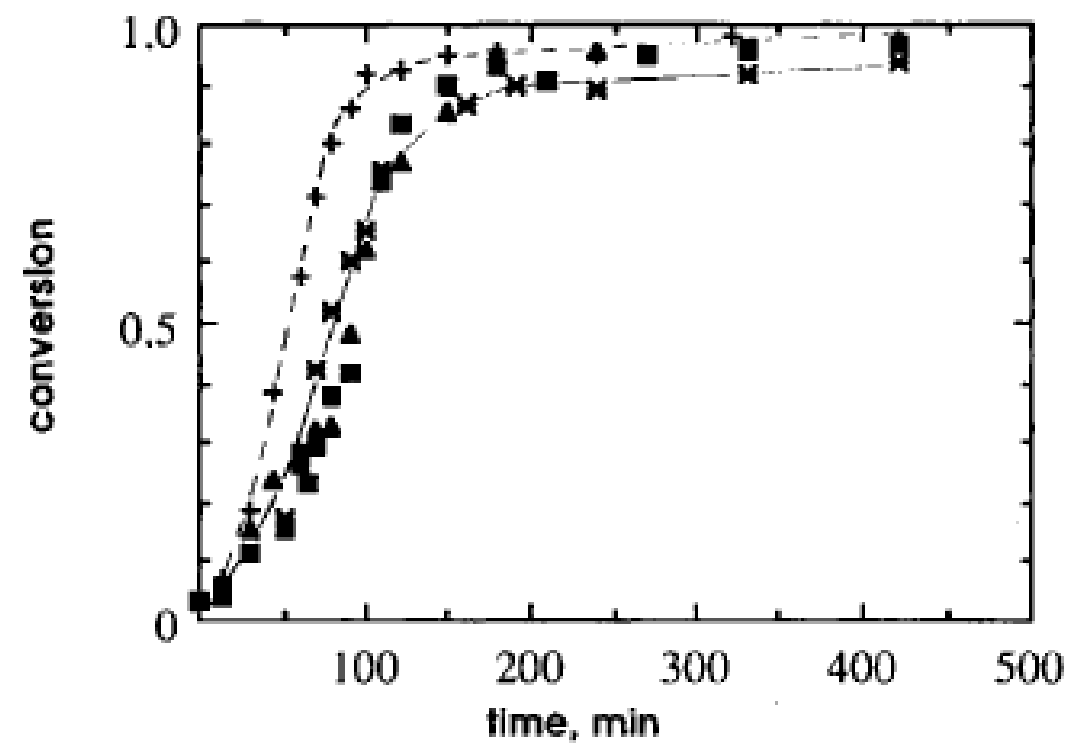

Fig. 1. Increase in conversion $x$ with time for various L10/elastomer blends (isothermal cure temperature $\left.T_{\mathrm{i}}: 180^{\circ} \mathrm{C}\right)$; $\boldsymbol{*}$ : Neat L10; $\mathbf{\square}: 15 \mathrm{wt} \%$ NFBN/L10 blend; $\boldsymbol{\Delta}: 15 \mathrm{wt} \%$ CTBN/L10 blend; $\mathbf{\uparrow}: 15$ wt\% ATBN/L10 blend. 


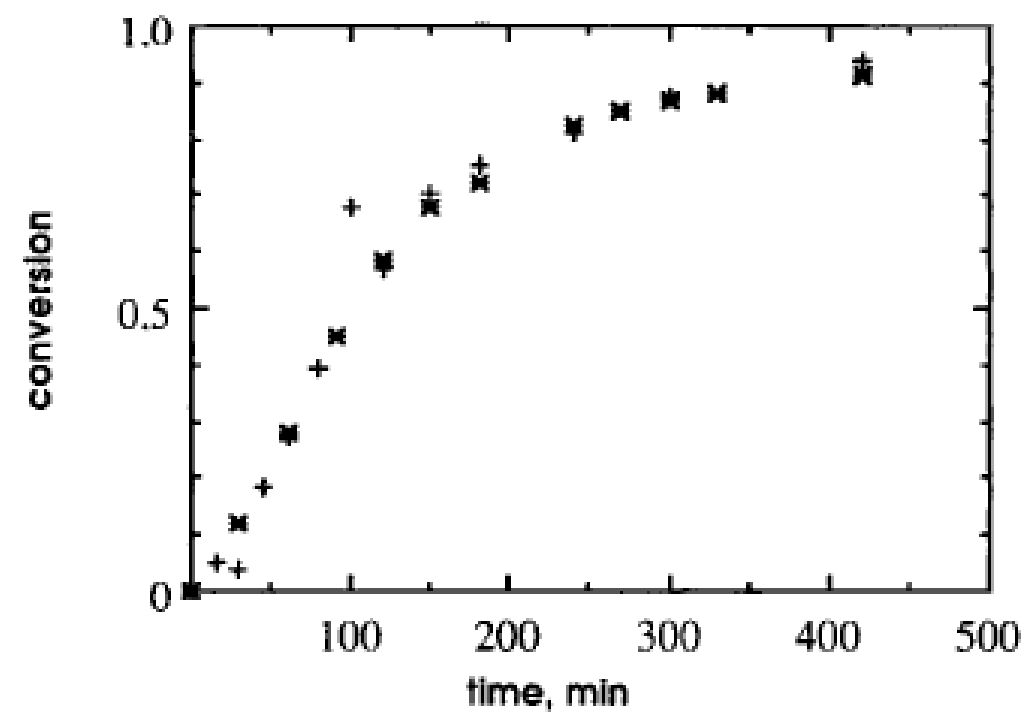

Fig. 2. Increase in conversion $x$ with time for neat $B 10$ and for its blend with NFBN $\left(T_{\mathrm{i}}=200^{\circ} \mathrm{C}\right)$. $*$ : Neat B10; +: 15 wt\% NFBN/B10 blend.

Furthermore, when the isothermal cure was performed under an inert atmosphere such as argon or vacuum, ${ }^{15,16}$ it was found that the relation between $x$ and $t$ was modified. Gelation occurs around 0.6 conversion under air, whereas the theoretical $x_{\text {gel }}=0.50$ is experimentally observed under argon. The autocatalytic character tends to disappear under argon. Although one may think that the air moisture is responsible for this difference, this explanation may not be quite satisfactory. We are currently investigating the curing process of neat dicyanates, as well as their potential catalysts. ${ }^{17}$ But it is not the purpose of this paper, which is to study the influence of different additives on the reaction rate under classic conditions, air.

All the rubber- or thermoplastic-modified cyanates we have studied are initially miscible at the curing temperature, $T_{\mathrm{i}}$. At a certain conversion, phase separation occurred as the molar mass of the cyanate oligomers increased and more-polar cyanate functional groups were transformed into less-polar cyanurate rings. The phase separation phenomenon can be observed very simply by the fact that the solution becomes cloudy (CP).

The conversion versus reaction time curves obtained for the blends of $\mathrm{L} 10$ and B10 with 15 wt\% rubber, are plotted in Figs 1 and 2. In the first part of the curves, it can be seen that the $x=f(t)$ relation is not modified by the addition of $15 \mathrm{wt} \%$ NFBN or CTBN, as compared with pure L10 or B10. On the other hand, the curve corresponding to the ATBN/L10 blend is different: it reacts faster than neat L10. Considering the $10 \%$ residual diamine (Unilink 4200) in ATBN, we determined the curve associated with a $1.74 \%$ Unilink $4200 /$ L10 blend (Fig. 3), which simulates the concentration of the excess free Unilink 4200 in a 15 wt\% ATBN/L10 blend. The mixture Unilink 4200/L10 reacts faster than neat L10 but slower than the blend with ATBN, especially at conversion $x>0.6$. This is explained by combining the effect of ATBN itself. 


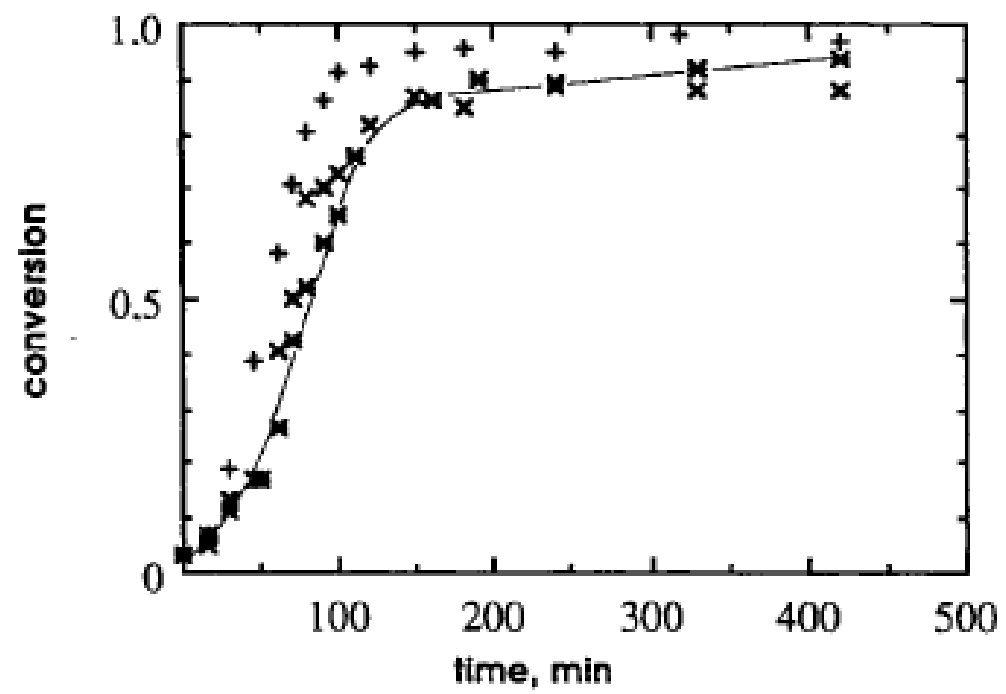

Fig. 3. Increase in conversion with time for neat $L 10$ and for its blends with ATBN and Unilink $4200\left(T_{i}\right.$ $\left.=180^{\circ} \mathrm{C}\right) . *$ : Neat L10; $\mathbf{+} 15$ wt\% ATBN/L10 blend; X: 1.74 wt\% Unilink 4200/L10 blend.

The $x=f(t)$ curves corresponding to the $15 w t \%$ and 20 wt\% NFBN/L10 blends are compared in Fig. 4 . It can be seen that the latter reacts a little slower, but only after $100-150 \mathrm{~min}$, i.e. after gelation (as determined by the presence of an insoluble fraction in tetrahydrofuran).

To try to improve the adhesion between the two phases and the mechanical properties (future studies), a blend of L10 with 14 wt\% NFBN plus 1 wt\% ATBN was also studied. The results plotted in Fig. 4 show that the concentration of amino-hydrogen is too low to modify the kinetics of reaction in this case.

From the results above, it can be concluded that the dilution effect due to the introduction of nonreactive rubbers into L10 or B10 only weakly influences the polymerization kinetics. The faster polymerization of ATBN/L10 blends may result from the reaction of the excess free Unilink 4200 and of the rubber amino end groups with cyanate functions, leading to an isourea linkage which can also have a catalytic effect for the polycyclotrimerization reaction.

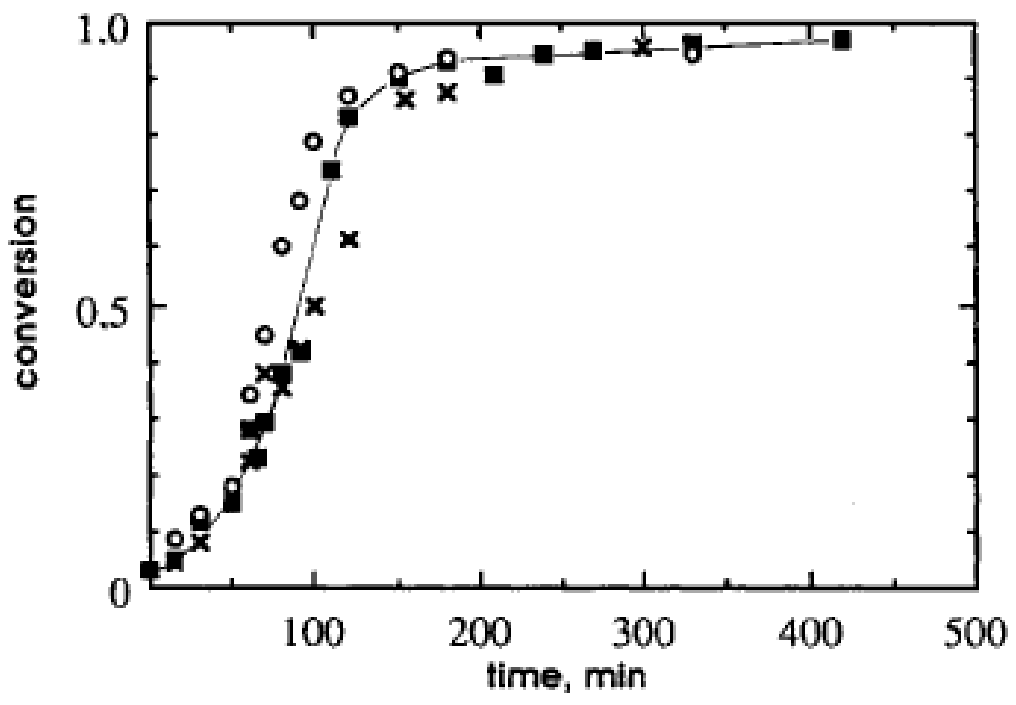

Fig. 4. Effect of the amount of rubber on the $x$ versus $t$ curve $\left(T_{\mathrm{i}}=180^{\circ} \mathrm{C}\right) . \mathbf{m}: 15 \mathrm{wt} \% \mathrm{NFBN} / \mathrm{L} 10$ blend; O: (14 wt\% NFBN + 1 wt\% ATBN)/L10 blend; X: 20 wt\% NFBN/L10 blend. 
In the last stages of the reaction, in the case of the neat systems, the conversion is limited to about 0.9 , as a result of vitrification. However, the conversion of all the rubber-modified systems easily reaches 0.95 or more, indicating that the vitrification effect is delayed and suggesting that part of the rubber dissolves in the matrix and decreases its $T_{\mathrm{g}}$. The same conclusion can be drawn from the glass transition temperatures of the final networks $\left(T_{\mathrm{g} \infty}\right)$, which are displayed in Table 4 . Such an effect is not observed for the mixture Unilink 4200/L10 (without rubber).

In addition, the conversions at which the isothermally cured blends became cloudy $\left(x_{\mathrm{cp}}\right)$ and the gel conversions $\left(x_{\mathrm{gel}}\right)$ were measured for neat L10 and B10 and for their blends with rubbers; the results are summarized in Table 4. It can be seen that for all the blends, phase separation occurs well before gelation ; the $x_{\text {gel }}$ values are practically the same for neat systems and blends, considering experimental error. Therefore, we can conclude that phase separation does not disturb the polymerization kinetics, nor the network build-up.

TABLE 4. Conversions at the cloud point $\left(x_{\mathrm{cp}}\right)$, at gelation $\left(x_{\mathrm{gel}}\right)$ and ultimate glass transition temperature $\left(T_{\mathrm{g} \infty}\right)$ of the networks based on neat L10 or B10 and their blends

\begin{tabular}{|l|l|l|l|l|l|}
\hline Reactive system & $\boldsymbol{T}_{\mathbf{i}}\left({ }^{\circ} \mathbf{C}\right)$ & $\boldsymbol{X}_{\mathrm{cp}}$ & $\boldsymbol{x}_{\text {gel }}$ & $\boldsymbol{T}_{\mathrm{g} \infty}\left({ }^{\circ} \mathrm{C}\right)$ & $\left(\boldsymbol{\Phi}_{\mathrm{a}}\right)_{\infty}{ }^{\mathrm{m} \boldsymbol{}}$ \\
\hline Neat L10 & 180 & - & 0.63 & 261 & \\
15 wt\% NFBN/L10 & 180 & 0.31 & 0.61 & 228 & 0.041 \\
15 wt\% CTBN/L10 & 180 & 0.39 & & 227 & 0.045 \\
15 wt\% ATBN/L10 & 180 & 0.46 & 0.61 & 213 & 0.072 \\
15 wt\% PES4100P/L10 & 180 & 0.44 & 0.72 & 252 & \\
15 wt\% PES 5003P/L10 & 180 & 0.40 & 0.59 & 260 & \\
30 wt\% PES 5003P/L10 & 180 & 0.55 & 0.58 & & \\
Neat B10 & 200 & - & 0.62 & 292 & \\
15 wt\% NFBN/B10 & 200 & 0.40 & 0.63 & 251 & 0.045 \\
\hline
\end{tabular}

${ }^{a}\left(\Phi_{a}\right)_{\infty}{ }^{m}$ represents the fraction of rubber dissolved in the fully cured matrix $(x=1)$ and is calculated from Fox's equation. 


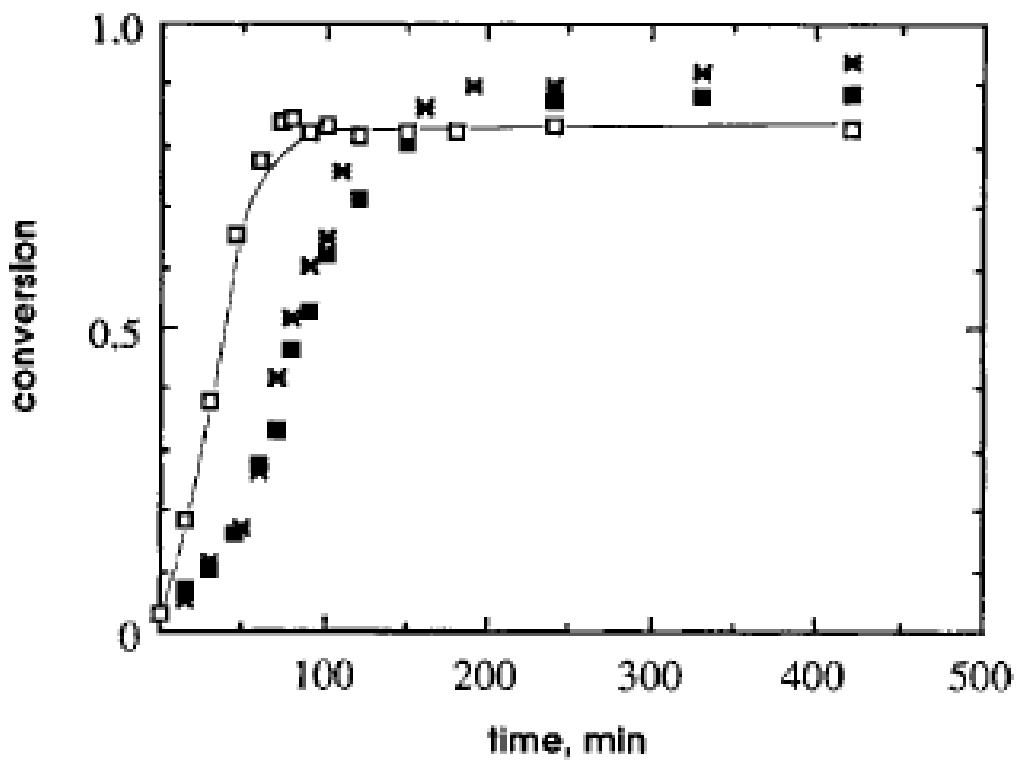

Fig. 5. Effect of PES additives on the $x$ versus $t$ curve $\left(T_{\mathrm{i}}=180^{\circ} \mathrm{C}\right)$. $*$ : Neat L10; $\bigotimes$ : 15 wt\% PES 4100P/L10 blend; $\square: 15$ wt\% PES 5003P/L10 blend.

We have also studied the influence of PES on the isothermal reaction rate. Figure 5 displays the conversion versus reaction time curves for neat L10, 15 wt\% PES 4100P/L10 and 15 wt\% PES 5003P/L10 blends. For the first two systems, the experimental data fall nearly on the same curve, while the system based on PES 5003P reacts faster. This result may be attributed to the different structures of the two PES: although PES 5003P has a higher molar mass than PES 4100P, the former also contains more hydroxyl groups, which can have a catalytic action in the polycyclotrimerization of cyanates ${ }^{7}$ or lead to the formation of adducts with cyanates in the same way as amino end groups for ATBN.

For PES 4100P and PES 5003P, the conversions at the cloud point are respectively 0.44 and 0.40 for $T_{\mathrm{i}}$ $=180^{\circ} \mathrm{C}$ (see Table 4). Once again, the dilution effect and phase separation are unlikely to influence the polycyclotrimerization kinetics.

Finally, the maximum conversion of the 15 wt\% PES 5003P/L10 blend is lower than that of the $15 \mathrm{wt} \%$ PES 4100P/L10. This can be attributed to a vitrification effect. Due to a possible reaction between additive chain ends and cyanate monomer, the mass fraction of PES 5003P dissolved in the matrix after phase separation may be higher than that of PES 4100P. Thus the vitrification of the former occurs earlier.

Another parameter reveals the catalytic character of ATBN and PES 5003P. The DSC scan allows the determination of the exotherm maximum temperature, $T_{\max .}{ }^{15-17}$ The addition of a catalyst to a reactive mixture lowers $T_{\max }$ compared with the neat system. In our case, $T_{\max }$ values were measured and are reported in Table 5 : it appears that $T_{\max }$ is (i) $10 \mathrm{~K}$ lower for the ATBN-based system, (ii) $20 \mathrm{~K}$ lower for the PES 5003P-based system, compared with pure L10. Except for the NFBN-based blend which, curiously, displays a higher $T_{\max }$, the other values remain practically unchanged. This is in good agreement with the previous results at one isothermal curing temperature, $T_{\mathrm{i}}$. 
TABLE 5. Exotherm maximum temperatures $\left(T_{\max }\right)$ during a DSC scan $\left(q=10^{\circ} \mathrm{C} / \mathrm{min}\right)$ for various reactive systems

\begin{tabular}{|l|c|}
\hline \multicolumn{1}{|c|}{ Reactive system } & $\boldsymbol{T}_{\max }\left({ }^{\circ} \mathrm{C}\right)$ \\
\hline Neat L10 & 264 \\
15 wt\% NFBN/L10 & 275 \\
15 wt\% CTBN/L10 & 263 \\
15 wt\% ATBN/L10 & 254 \\
15 wt\% PES 4100P/L10 & 268 \\
15 wt\% PES 5003P/L10 & 244 \\
\hline
\end{tabular}

\section{Glass transition temperature}

Figures 6 and 7 display the increase in $T_{\mathrm{g}}$ with the cyanate conversion $x$, for neat L10 and B10 systems. In previous work, we demonstrated that in this case the $T_{\mathrm{g}}-x$ curve could be fitted to DiBenedetto's equation, as restated by Pascault \& Williams: ${ }^{18}$

$$
\frac{T_{g}-T_{g 0}}{T_{g \infty}-T_{g 0}}=\frac{\lambda x}{1-(1-\lambda) x}
$$

where $T_{\mathrm{g} 0}$ and $T_{g \infty}$ correspond respectively to the glass transition temperatures of the monomer and of the fully cured $(x=1)$ network, and $\lambda=\Delta C_{p \infty} / \Delta C_{p 0}$, where $\Delta C_{p \infty}$ and $\Delta C_{p 0}$ are respectively the isobaric heat capacity changes of the fully cured network and of the monomer.

These parameters can be measured by DSC and are summarized in Table 6 .

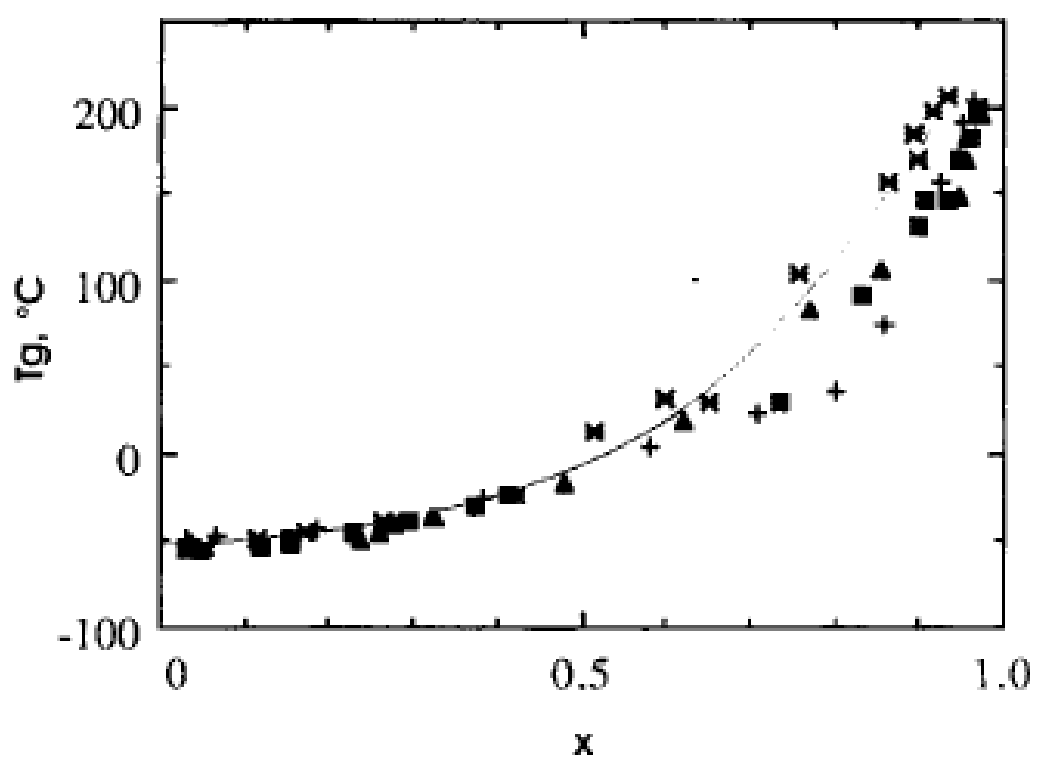

Fig. 6. Evolution of $T_{\mathrm{g}}$ with $x$ for neat $\mathrm{L} 10$ and for its blends with different rubbers $\left(T_{\mathrm{i}}=180^{\circ} \mathrm{C}\right)$. * : Neat L10; 15 w t\% NFBN/L10 blend; $\mathbf{\Delta}: 15$ wt\% CTBN/L10 blend; +: 15 wt\% ATBN/L10 blend. 


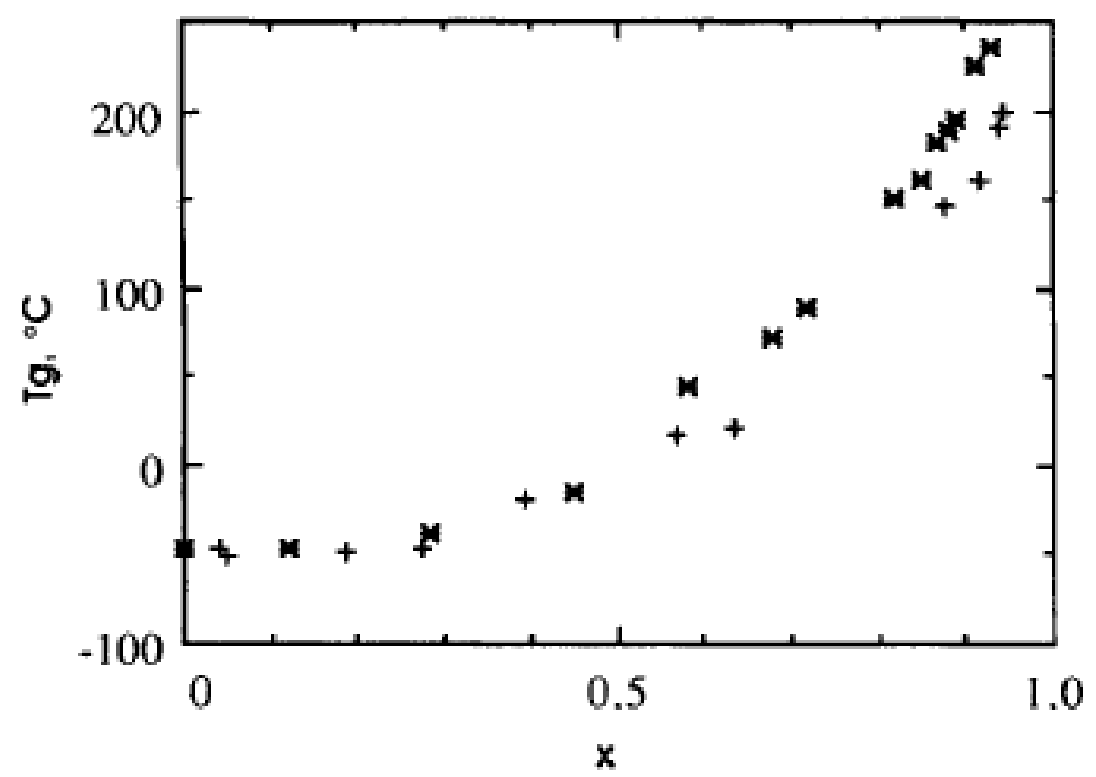

Fig. 7. Effect of the addition of non-reactive rubber on the $T_{\mathrm{g}}-x$ relation for $\mathrm{B} 10$ cured at $200^{\circ} \mathrm{C}$. $*$ : Neat B10; +: 15 wt\% NFBN/B10 blend.

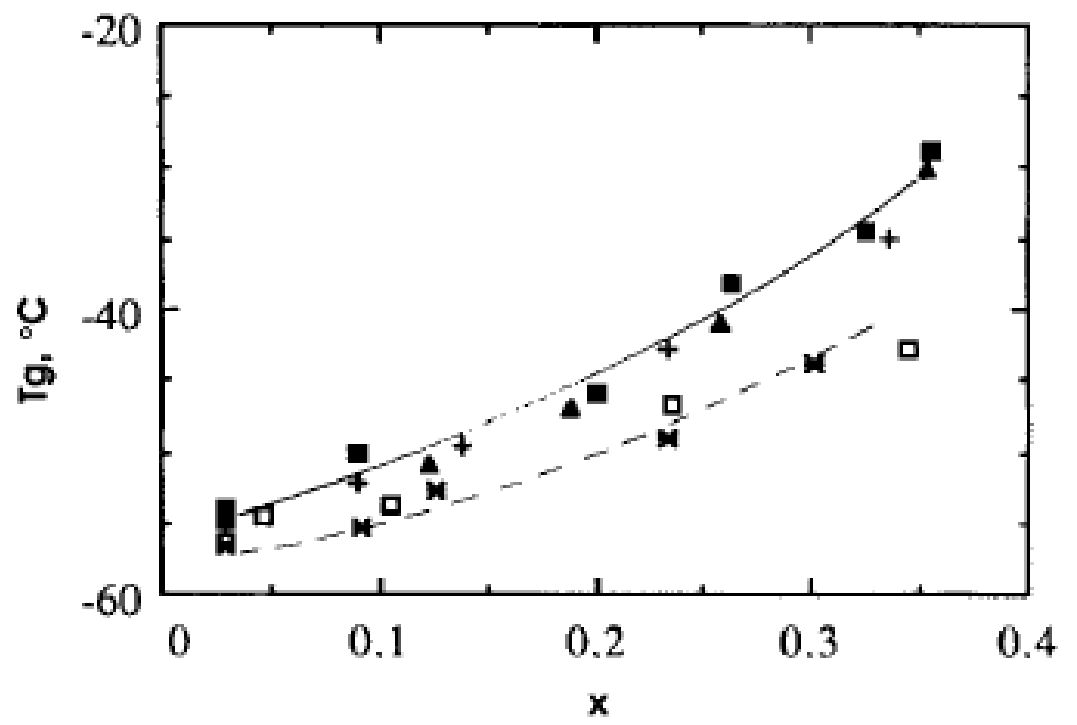

Fig. 8. Effect of the amount of rubber on the $T_{\mathrm{g}}-x$ relation for NFBN/L10 blends $\left(T_{\mathrm{i}}=180^{\circ} \mathrm{C}\right)$. $\mathbf{\mathbf { a }}: 3 \mathrm{wt} \%$ NFBN; $\boldsymbol{\Delta}: 6$ wt\% NFBN; $\mathbf{4}: 10$ wt\% NFBN; $\square: 15$ wt\% NFBN; $*: 20$ wt\% NFBN.

For the rubber- or thermoplastic-modified cyanates, only one $T_{\mathrm{g}}$ was observed by DSC for all of the blends. After phase separation this $T_{\mathrm{g}}$ is evidently the $T_{\mathrm{g}}$ of the matrix, because DSC is not precise enough to measure the $T_{\mathrm{g}}$ of the dispersed phase.

Figure 6 shows that the evolution of $T_{\mathrm{g}}$ with $x$ for the three L10 blends with 15\% NFBN, 15\% CTBN and $15 \%$ ATBN is almost the same. At the same conversion, the $T_{\mathrm{g}}$ of the blends $T_{\mathrm{g}, \mathrm{m}}$ are at first about identical to that of the neat L10, but at higher conversion, $x>0.5$, they become lower. This behaviour can be qualitatively explained by Fox's equation:

$$
\frac{1}{T_{g, m}}=\frac{\Phi_{c}}{T_{g, c}}+\frac{\Phi_{a}}{T_{g, a}}
$$


where $T_{\mathrm{g}, \mathrm{m}}, T_{\mathrm{g}, \mathrm{c}}$ and $T_{\mathrm{g}, \mathrm{a}}$ stand for the glass transition temperatures of the matrix of the blend and of its components c (cyanate) and a (additive); $\Phi_{c}$ and $\Phi_{a}$ represent their mass fractions in the matrix.

The $T_{\mathrm{g}}$ values of $\mathrm{L} 10$ and B10 oligomers and their fully cured networks, and of the rubbers are given in Tables 2 and 6.

When $\mathrm{x} \leq 0.4,\left(T_{\mathrm{g}}\right)_{x}$ relative to the neat cyanate at conversion $x$ increases slowly; thus the difference $\left(T_{\mathrm{g}, \mathrm{c}}\right)_{x}-T_{\mathrm{g}, \mathrm{a}}$ remains low, $40^{\circ} \mathrm{C}$ at $x=0.4$ for example, and $\left(T_{\mathrm{g}}\right)_{x} \approx\left(T_{\mathrm{g}, \mathrm{c}}\right)_{x}$. For the blends once phase separation has occurred (at $x=0.30-0.46$, depending on the rubber, see Table 4), $\Phi_{a}$ decreases markedly, but apparently does not reach zero since afterwards $\left(T_{\mathrm{g}}\right)_{x}$ is higher than $\left(T_{\mathrm{g}, \mathrm{m}}\right)_{x}$. If part of the rubber remains dissolved in the matrix, $\Phi_{\mathrm{a}}>0$ and, since beyond $x=0.4,\left(T_{\mathrm{g}, \mathrm{c}}\right)_{x}>>\left(T_{\mathrm{g}, \mathrm{a}}\right)_{x}$, then according to Fox's equation we have also $T_{\mathrm{g}, \mathrm{c}}>T_{\mathrm{g}, \mathrm{m}}$ in that case.

TABLE 6. Characteristic temperatures and isobaric heat capacity changes of the neat L10 and B10 and of their fully reacted networks (from Refs 15 and 16)

\begin{tabular}{|c|c|c|c|c|c|}
\hline Monomer & $\boldsymbol{T}_{\mathrm{g} 0}\left({ }^{\circ} \mathrm{C}\right)$ & $\boldsymbol{T}_{\mathrm{g} \infty}\left({ }^{\circ} \mathrm{C}\right)$ & $\Delta C_{\mathrm{p} 0}(\mathrm{~J} / \mathrm{gK})$ & $\Delta C_{\mathrm{p} \infty}(\mathrm{J} / \mathrm{gK})$ & $\boldsymbol{\lambda}$ \\
\hline L10 & -53 & 261 & 0.56 & 0.21 & 0.375 \\
B10 & -48 & 292 & 0.56 & 0.13 & 0.232 \\
\hline
\end{tabular}

In fact, when $T_{\mathrm{g}}-x$ curves of different mass fraction NFBN/L10 blends are plotted on a larger scale (Fig. 8), it can be seen that, at a given conversion, $T_{\mathrm{g}}$ decreases almost regularly with increasing total rubber fraction in the blend, $\Phi_{a}$. This might result from the increase of rubber fraction in the matrix with increasing $\Phi_{\text {a. }}$.

The ultimate glass transition temperatures $\left(T_{\mathrm{g} \infty}\right)$ of the different systems were measured by a second DSC scan at a heating rate of $7.5 \mathrm{~K} / \mathrm{min}$; they are displayed in Table 4 . Using these values, the fraction of rubber dissolved in the fully cured matrix, $\left(\Phi_{\mathrm{a}}\right)_{\infty}{ }^{\mathrm{m}}$, was calculated by Fox's equation and the results are given also in Table 4. It appears that $\left(\Phi_{a}\right)_{\infty} \mathrm{m}$ is much lower than the initial $\Phi_{a, 0}$, which shows that most of the rubber can be found in the dispersed phase resulting from the polymerization-induced phase separation. The $\left(\Phi_{\mathrm{a}}\right)_{\infty}{ }^{\mathrm{m}}$ corresponding to the $15 \mathrm{wt} \%$ ATBN/L10 blend is higher than the others, consistent with its higher miscibility with L10.

Finally, the influence of the nature of the dicyanate monomer was examined. The increase in $T_{\mathrm{g}}$ with $x$ for $15 \mathrm{wt} \%$ NFBN/B10 blend is depicted in Fig. 7 and compared with that of neat B10. The evolution is exactly the same as that observed between neat L10 and the 15 wt\% NFBN/L10 blend.

Similarly, the $T_{\mathrm{g}}-x$ curves of the PES-modified cyanates were measured. Figure 9 shows that for $x \leq 0.4$, at a given conversion, the $T_{\mathrm{g}}$ of the $15 \mathrm{wt} \%$ PES 4100P/L10 blend is a little higher than that of the neat monomer, whereas for $x=0.4$ both systems have the same $T_{\mathrm{g}}$ for a given conversion. However, the $T_{\mathrm{g}}$ versus $x$ curve for the $15 \mathrm{wt} \%$ PES 5003P/L10 blend lies slightly above the other two. Once again, Fox's equation can be used to account for these observations; before phase separation, if we consider that in the case of PES $T_{\mathrm{g}, \mathrm{a}} \gg T_{\mathrm{g}, \mathrm{c}}$ (whatever the conversion may be) then the $\left(T_{\mathrm{g}, \mathrm{m}}\right)_{x}$ of the blend may well be higher than $\left(T_{\mathrm{g}}\right)_{x}$. After phase separation $(x>0.4)$, two different situations may be encountered: 
(i) in the case of PES 4100P, practically no additive remains in the matrix, and the $T_{\mathrm{g}}$ measured for the blend corresponds exactly to that of the neat system with the same conversion, making the two $T_{\mathrm{g}}-x$ curves merge;

(ii) in the case of PES 5003P, some additive remains dissolved in the matrix and the glass transition temperature of the latter remains higher than that of the corresponding neat system. This may be due to the presence of more hydroxyl groups in PES 5003P and to their possible reaction with cyanate groups (see above), although the overall miscibility of PES 4100P with L10 seems to be higher than that of PES 5003P because of the lower molar mass of the former. ${ }^{19}$ Besides, the $T_{\mathrm{g}}$ of PES 5003P is a little higher than that of PES 4100P (Table 3).

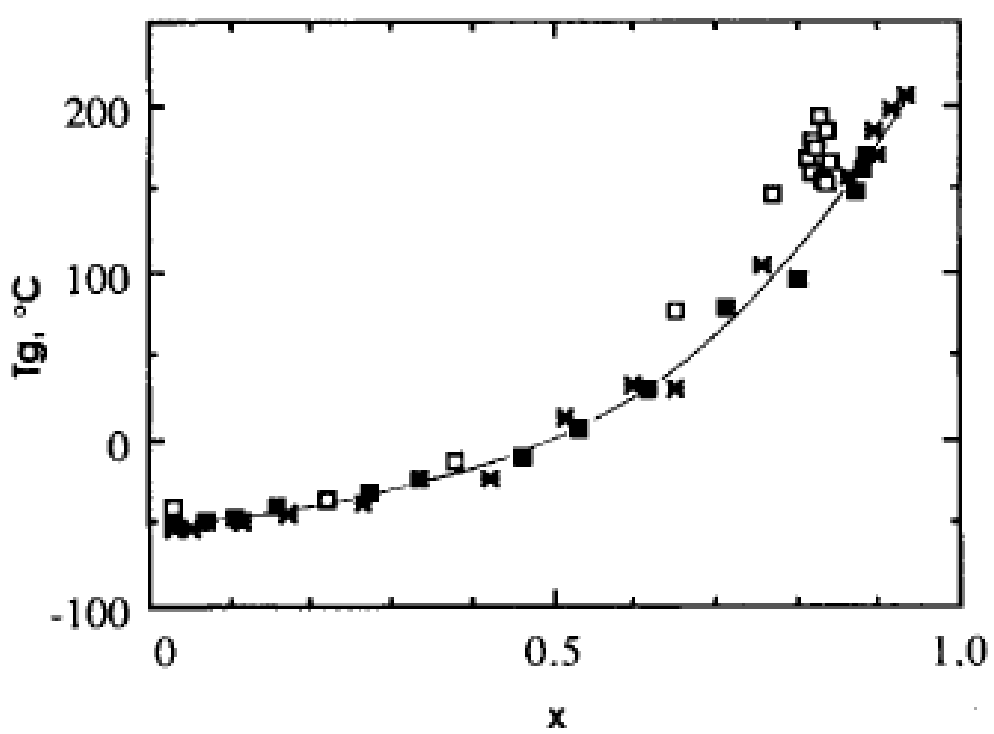

Fig. 9. Evolution of $T_{\mathrm{g}}$ with $x$ for PES-modified L10 systems $\left(T_{\mathrm{i}}=180^{\circ} \mathrm{C}\right)$. *: Neat L10; $囚: 15 \mathrm{wt} \%$ PES 4100P/L10 blend; $\square: 15$ wt\% PES 5003/L10 blend.

In the same way, the relative positions of both <-x curves explain why vitrification is more delayed in the case of PES 4100P (see kinetic section above); the conversion at which $<==180^{\circ} \mathrm{C}$ is equal to 0.8 for the 15 wt\% PES 5003P/LIO blend, and to 0.95 for the 15 wt\% PES 4100P/L10 blend. This is the reason why the maximum conversion reached by the former, when cured isothermally at 180 " $C$, is lower.

\section{CONCLUSIONS}

The polycyclotrimerization of two aromatic dicyanates monomers has been investigated in the presence of various amounts of different rubber or thermoplastic additives. It seems that the polymerization reaction is only slightly disturbed by the presence of these additives, except when the latter display catalytic functional groups or impurities, especially with labile hydrogen atoms (hydroxyl or amine groups). The additives have a marked influence only on the onset of vitrification (i.e. the time when the reaction becomes diffusion-controlled).

The evolution of $T_{\mathrm{g}}$ with the conversion $x$ can qualitatively be described by Fox's equation, assuming that after phase separation part of the additive remains dissolved in the matrix. Then it is possible to consider that the rubbers lower the glass transition temperatures of the resulting networks. The 
phenomenon is all the more pronounced as the rubber is more miscible with the dicyanate monomer, or is added in higher quantities. In the same way, PES additives can increase the $T_{\mathrm{g}}$ of the final blend, as compared with the pure homopolymer network. However, these effects on $T_{\mathrm{g}}$ strongly depend on the nature of the chain ends or functional groups of the additives.

The phase diagrams and miscibilities of the various blends presented here will be completed and discussed in more detail in a coming paper.

\section{REFERENCES}

1. Müllhaupt, R., Chimia, 44 (3) (1990) 43.

2. Rozenberg, B. A., Makromol. Chem., Macromol. Symp., 41 (1991) 165.

3. Riew, C. K. \& Gillham, J. K. (Eds), Rubber Modified Thermoset Resins. Adv. Chem. Ser. 208, American Chemical Society, Washington DC, 1984 (and references therein).

4. Riew, C. K. (Ed.), Rubber-Toughened Plastics. Adv. Chem. Ser. 222, American Chemical Society, Washington DC, 1989 (and references therein).

5. Verchère, D., Sautereau, H., Pascault, J. P., Moschiar, S. M., Riccardi, C. C. \& Williams, R. J. J., J. Appl. Polym. Sci., 41 (1990) 467.

6. Chen, D., Pascault, J. P. \& Sautereau, H., Polym. Int., 32 (1993) 361.

7. Shimp, D. A., Christenson, J. R. \& Ising, S. J., Rhône-Poulenc Inc., Performance Resins \& Coatings Division Publication, Louisville, KY, USA, 1990.

8. Yang, P. C., Pickelman, D. M. \& Woo, E. P., 35th Int. SAMPE Symp. Proc., 2-5 April, 1990, p. 1131.

9. Almen, G., McKenzie, P., Malhotra, V. \& Maskell, R., 35th Int. SAMPE Symp. Proc., 2-5 April 1990, p. 408.

10. Frank, W. L. \& Maureen, A. B., SAMPE Eur. Chap., Switzerland, 1990, p. 57.

11. Yang, P. C., Woo, E. P., Laman, S. A., Jakulowski, J. J., Pickelman, D. M. \& Sue, H. J., 36th Int. SAMPE Symp. Proc., 15-18 April 1991, p. 437.

12. Verchère, D., Sautereau, H., Pascault, J. P., Moschiar, S. M., Riccardi, C. C. \& Williams, R. J. J., Polymer, 30 (1989) 107.

13. Gupta, A. M., Macromolecules, 24 (1991) 3459.

14. Simon, S. L. \& Gillham, J. K., J. Appl. Polym. Sci., 47 (1993) 461.

15. Georjon, O., Galy, J. \& Pascault, J. P., J. Appl. Polym. Sci., 44 (1993) 1441.

16. Mirco, V., Cao, Z. Q., Méchin, F. \& Pascault, J. P., ACS Polym. Mater. Sci. Eng. Div. Prepr., 66 (1992) 451.

17. Mirco, V., Méchin, F. \& Pascault, J. P., STEP13 Proceedings, Montpellier 1-3 June 1993.

18. Pascault, J. P. \& Williams, R. J. J., J. Polym. Sci., Polym. Phys. Ed., B28 (1990) 85.

19. Cao, Z. Q. \& Pascault, J. P., to be published. 